\title{
KEPEMIMPINAN PENDIDIKAN YANG INOVATIF
}

\author{
Aminuddin Syam \\ Dosen Fakultas Tarbiyah IAIN Imam Bonjol Padang \\ e-mail: amin_amin@ymail.com
}

\begin{abstract}
The government policy on autonomy of education should be followed by the inovation in many components of education institutions, especially in their management level. The appropriate management in autonomous era is that the existence of inovative leadership. In other words, they have clear vision, mission, will, and commitment to do inovations. Thus, the education institution under this inovative leadership will reach their aims based the autonomy demands quickly.
\end{abstract}

\begin{abstract}
Abstrak: Kebijakan pemerintah di bidang pendidikan yaitu dengan diberlakukannya otonomi pendidikan perlu diiringi dengan inovasi pada berbagai komponen institusi pendidikan, termasuk inovasi dalam kepemimpinan pendidikan. Kepemimpinan pendidikan yang tepat di era otonomi pendidikan tersebut adalah kepemimpinan pendidikan yang inovatif, yaitu kepemimpinan yang memiliki kemampuan untuk melakukan inovasi di lembaga pendidikan. Ia harus memiliki visi, misi, kemauan dan komitmen untuk melakukan inovasi, memahami proses melakukan inovasi dan memiliki kemampuan dalam melakukan inovasi. Dengan demikian, pendidikan yang berada dalam pengelolaannya akan dapat dilakukan inovasi ke arah yang lebih baik sesuai dengan tuntutan otonomi pendidikan.
\end{abstract}

Kata Kunci: Pendidikan, kepemipinan yang inovatif, otonomi pendidikan.

\section{PENDAHULUAN}

Sebelum otonomi pendidikan diberlakukan, kepemimpinan pendidikan yang dilaksanakan saat itu adalah kepemimpinan pendidikan sentralistik (Umaidi, 1999:2). Kepemimpinan pendidikan sentralistik menggunakan strategi input-output dan macro oriented. Dalam strategi input-output, jika semua input pendidikan telah dipenuhi dalam pengelolaan pendidikan, maka pendidikan akan menghasilkan pendidikan yang bermutu. Sedangkan menurut strategi macro oriented, pengelolaan pendidikan diatur oleh jajaran pendidikan ditingkat pusat, sedangkan kepemimpinan pendidikan di tingkat sekolah hanya melaksanakan semua ketentuan yang telah ditetapkan ditingkat pusat, dengan cara demikian diharapkan dapat diperoleh peningkatan mutu pendidikan (Umaedi, 1999:2).

Setelah diberlakukan otonomi daerah termasuk otonomi pendidikan dengan Peraturan Pemerintah Nomor 25 tahun 2000, maka kepemimpinan pendidikan di sekolah harus menyesuaikan pula dengan peraturan tersebut. Kepemimpinan pendidikan yang cocok di era otonomi pendidikan itu adalah kepemimpinan yang inovatif. Kepemimpinan yang inovatif adalah kepemimpinan yang mampu melakukan perubahan atau inovasi dalam intitusi pendidikan.

Kepemimpinan pemndidikan yang inovatif di era otonomi pendidikan ini sangat dibutuhkan karena: (1) corok hidup dan fungsi manusia berubah dengan pertambahan usia, (2) dunia dan kehidupan manusia mengalami perubahan dari waktu ke waktu. Bahkan pemikiran modern mengatakan kepemimpinan pendidikan tidak hanya mampu menyesuikan diri pada dunia kehidupan yang berubah, tetapi juga berperan dalam menciptakan dan pengendalian perubahan itu. (Aminuddin Syam, 2006).

\section{TUJUAN PENULISAN}

Tujuan penulisan ini tulisan ini adalah :

1. Untuk memberikan wawasan kepada kepemimpinan pendidikan dalam melakukan inovasi pendidikan pada institusi pendidikan (sekolah).

2. Agar terjadi perubahan paradigma kepemimpinan pendidikan pada institusi dari kepemimpinan sentralistik kepada kepemimpinan pendidikan yang inovatif sesuai dengan tuntutan otonomi pendidikan. 
3. Agar dipeoleh peningkatan mutu pendidikan dibawah kepemimpinan pendidikan yang inovatif.

\section{METODE PENULISAN}

Penulisan tulisan ini menggunakan metode penulisan deduktif dan induktif (Iarajasah, 2001:1). Penggunaan metode deduktif dilakukan dengan cara memulai tulisan ini dari konsep kemudian dilanjutkan dengan uraian untuk melengkapi dan memudahkan memahami tulisan ini. Tulisan ini juga menggunakan penggunaan metode penulisan induktif dengan cara memulai dari uraian kemudian diberikan kesimpulan seperlunya sehingga tulisan dapat dipahami lebih baik.

\section{PEMBAHASAN}

Kepemimpinan pendidikan sentralistik telah dilaksanakan di Indonesia semenjak beberapa dasawarsa dengan harapan dapat meningkatkan mutu pendidikan. Kepemimpinan pendidikan sentralistik menerapkan strategi input-output. Dalam strategi input-output, jika semua input pendidikan telah dipenuhi dalam pengelolaan pendidikan, seperti penyediaan buku-buku dan alat belajar, sarana prasarana, peningkatan mutu guru melalui pendidikan dan pelatihan, maka pendidikan akan menghasilkan pendidikkan yang bermutu sesuai dengan yang diharapkan (Umaedi, 1999:2). Harapan ini tidak dapat diwujudkan karena strategi input autput kurang memperhatikan proses pendidikan. Input pendidikan merupakan hal yang diperlukan dalam batas-batas tertentu, tetapi tidak menjamin tercapainya peningkatan mutu pendidikan. Karena itu strategi input ouput tidak sesuai di institusi pendidkan, tetapi lebih tepat digunakan dalam bidang perusahaan.

Belum berhasil intitusi pendidikan meningkatkan mutu pendidikan karena kepemimpinan pendidikan pada masa lalu menggunakan strategi macro oriented, Dalam strategi macro oriented pengelolaan pendidikan diatur oleh jajaran pendidikan ditingkat pusat, sedangkan kepemimpinan pendidikan di tingkat sekolah (intitusi pendidikan) hanya melaksanakan semua ketentuan yang telah ditetapkan ditingkat pusat, dengan cara demikian diharapkan dapat diperoleh peningkatan mutu pendidikan (Umaedi, 1999:2). Harapan untuk meningkatkan mutu pendidikan tidak pernah menjadi kenyataan karena strategi pendidikan yang demikian mematikan inspiratif, kereativitas dan aktivitas sekolah. Pada hal sekolah harus diberikan kepercayaan untuk melakukan inovasi pada sekolahnnya sesuai dengan kebutuhan peserta didik, kondisi lingkungan, perkembangan ilmu pengetahuan dan teknologi. Walaupun demikian agar mutu pendidikan tetap terjaga, dan proses peningkatan mutu pendidikan tetap terpelihara, maka harus ada standar pendidikan yang ditetapkan secara nasional yang menjadi acuan dan pedoman bagi setiap komponen penyelengaraan pendidikan. Standar nasional pendidika itu adalah sebagai berikut : (1) standar isi, (2) stnadar proses, (3) standar kompetensi lulusan, (4) standar pendidik dan tenaga kependidikan, (5) standar sarana dan prasarana, (6) standar pengelolaan, (7) standar pembiayaan, dan (8) standar pembiayaan pendidikan (PP No. 19 Tahun 2005 tentang Standar Nasional Pendidikan).

Kurang berhasilnya peningkatan mutu pendidikan pada masa ssentralistik juga disebabkan oleh: (1) kepemimpinan pendidikan tidak memiliki otonomi dalam mengelola pendidikan, (3) kurangnya ketarampilan yang dmiliki kepempimpinan pendidkikan dalam mengelola pendidikan, (3) kepemimpinan pendidikan kurang mampu dalam membina tim kerja yang solid, dan (4) kepemimpinan pendidikan kurang memiliki kemampuan dan klualitas (Umaedi, 1999:2). Sebagai dampaknya adalah rendahnya kualitas mutu pendidikan.

Pada era otonomi pendidikan sekarang ini pimpinan pendidikan diberi kewenangan yang lebih luas untuk melakukan inovasi terhadap pendidikan. Kepemimpinan pendidikan yang inovatif adalah kepemimpinan pendidikan yang mampu bersinergi dengan sumber daya pendidikan yang ada di sekolah untuk melakukan inovasi terhadap pendidikan sehingga melahirkan keunggulan-keunggulan di sekolah yang berfungsi sebagai percepatan peningkatan mutru pendidikan. Sumber daya pendidikan tersebut dapat berupa guru, siswa, 
sarana prasarana, dana, fasilitas, iklim dan lingkungan belajar (Sudarwan Danim, 2003:54).

Melakukan inovasi terhadap pendidikan merupakan pekerjaan yang rumit dan kompoleks serta belum dapat dipastikan hasilnya. Karena itu pekerjaan yang lebih sukar merencanakannya, lebih meragukan akan keberhasilannya dan lebih sulit dalam mengelolanya adalah melakukan inovasi (perubahan) (Everent, M. Rongers, 1993:1), sehingga banyak orang yang mengetahui dan memahami tentang suatu inovasi itu bermanfaat tetapi belum mau menerima apalagi melakukannya.

Hambatan lain dalam melakukan inovasi adalah: (1) mental block baries, yaitu hambatan yang diitmbulkan oleh sikap mental, seperti salah persepsi, takut gagal, tidak mau menanggung resiko, dan sebagainya, (2) cultural block, yaitu hambatan budaya yang sudah mengakar dan sulit diubah, dan (3) social block, yaitu hambatan social (Aan Komariah dan Cepi Triatna, 2005:26).

Melakukan inovasi sering menimbulkan rasa takup pada banyak orang (Arcaro, 2005:vi). Rasa takut untuk melakukan inovasi dapat dikurangi atau dihilangkan jika orang tersebut memiliki komitmen untuk melakukan inovasi. Jadi, komitmen dalam melakukan inovasi dapat mengurangi dan menghilangkan rasa takut dalam melakukkan inovasi (perubahan). Sedangkan kesuliitan dalam melakukan perubahan dapat diatasi dengan memiliki visi masa depan dalam melakukan inovasi.

Kepemimpinan inovatif harus mampu melakukan perubahan terhadap persepsi dan sikap semua komunitas sekolah terhadap inovasi (perubahan) yang dilakukan, sehingga semua komunitas sekolah dapat berinovasi dan mendukung terhadap inovasi yang dilakukan sekolah dalam rangka menghasilkan sekolah yang lebih baik. Karena tanpa dukungan semua komunitas sekolah perubahan kearah yang lebih baik melalui inovasi hanya akan merupakan impian.

Inovasi akan dapat dilakukan jika ada kemauan untuk berinovasi, tidak senang dengan kemapanan, tidak puas dengan hasil yang ada, dan selalu ingin lebih baik. Inovasi juga akan dapat dilaksanakan dengan baik jika memahami proses melakukan inovasi (perubahan) dan sistem pengelolaan inovasi (perubahan) (Ibrahim, 1988:5). Inovasi akan diwujudkan jika pemipin pendidikan mempunyai komitmen yang kuat, program yang jelas, keahlian dan kualitas (Agus Darma, 2003:39). Komitmen dalam melakukan inovasi merupakan syarat utama karena keberhasilan inovasi sangat ditentukamn oleh kuat atau tidaknya komitmen yang dimiliki oleh pemimpin pendidikan (Arcaro, 2005: ix). Oleh karena itu, banyak pemimpin pendidikan yang gagal dalam melakukan inovasi karena tidak mempunyai komitmen yang kuat dalam melakukan inovasi tersebut.

Di samping komitmen, program yang jelas dalam melakukan inovasi juga penting (Arcaro, 2005: xi). Program itu hendaknya dibuat secara rinci dengan memperimbangan faktor internal dan faktor eksternal intitusi pendidikan serta dilengkapi dengan petunjuk pelaksanaan sehingga menjadi pedoman bagi semua komuinitas intitusi pendidikan dalam melakukan inovasi. Program itu secara berkesinambungan harus diperbaharui atau disempurnakan untuk mencerminkan inovasi yang dlakukan.

Keahlian diperlukan agar kepemimpinan yang inovatif tidak mengalami kesulitan yang berarti dalam melakukan inovasi terhadap inntitusi pendidikan yang dipimpinnya. Keahlian yang harus dimilki oleh kepemimpinan yang inovatif adalah keahlian manajerial dan kehlian kepemimpinan. Keahlian manajerial diperlukan pemimpin yang inovatif mampu menangani komlesitas institusi pendidikan, yaitu memiliki keahlian dalam perencanaan strategic, dan operasional yang jujur, mampu mengorgansasikan pendidikan secara terkoordinasi, dan mampu mengevaluasi secara realibel dan valid.

Sedangkan keahlian kepemimpinan diperelukan agar dipereoleh pemimpin yang efektif, yaitu: pemimpin yang mampu: (1) membangun motivasi komunitas institusi pendidikan, (2) menentukan arah dan menangani perunahan secara tepat dan benar, dan (3) menjadim katalisator yang dapat yang dapat mewarnai sikap dan prilaku komunmitas lembaga pendidikan dalam bekerja (An Komariah, 2005:74). 
Kedua keahlian itu tidak dapat dipisahkan satu sama lain karena tanpa keahlian manajerial seseorang pemimpin akan kesulitan menetapkan langkah-langkah kerja rasional berdasarkan nilai-nilai teoritis dan praktis dalam pengembangan institusi pendidikan. Kondisi demikian dapat menimbulkan kemandekan dan mismanagemen yanhg disebabkan kurangnya kemampuan pemimpin dalam menentukan langkah-langkah manajerial. Sebaliknya, manajer yang tidak memiliki keahlian memimpin maka institusi pendidikan yang dimpinpinnya akan jalan di tempat, dan bahkan secara perlahan-lahan intitusi pendidikan itu akan mengalami kemunduran, karena tidak mampu memberikan inspirasi dan motivasi terhadap komunitas intitusi pendidikan yang dipimpinnya serta menentukan arah intitusi pendidikan yang dimpinpinya pada masa depan.

Selain memiliki keahlian, kepemimpin pendidikan yang inovatif juga harus memiliki kualitas. Kualitas kepempinan diperlukan agar dapat melakukan inovasi secara baik dan bijaksana. Kualitas kepemimpinan yang inovatif itu antara lain; (1) Memahami visi dengan baik dan mengetahui cara mencapaimnya, (2) integritas, adalah ketaatan pada nilai-nilai moral dan etika yang diyakininya dapat membentuk prilakunya menjadi manusia yang memiliki harkat dan martabat. Nilai-nilai etika dan moral itu antara lain : (a) dapat dipercaya, kepercayaan itu diperolehnya dengan sukareka dan tidak diragukan oleh semua komunitas institusi pendidikan, (b) konsisten, adalah dapat diandalkan karena taat pada asas perkataannya dan mengoperasionalkan kebijakan pendidikan secara tegas dan bijaksana, (c) komitmen, adalah terikat secara emosional dan intelektual untuk mengabdikan diri secara penuh bagi kepentingan pendidikan, (d) bertanggung jawab, kepemimpinan pendidikan yang inovatif sadar secara sosial, hokum dan moral berprilaku yang dapat dipertanggung jawabkan dalam melaksanakan perannya dalam pendidikan, (e) terkendali, yaitu pemimpin pendidikan secara emosional terkendali pemikirannya dan interaksinya dengan komunitas institusi pendidikan dan dengan orang lain.

Di samping itu, kepemimpinan pendidikan yang inovatif harus pula memiliki kualitas dalam mentrasformasikan kepada komunitas institusi pendidikan yang dipimpinnya konsep empati, yaitu: (1) inceliced influence, adalah prilaku yang menghasilkan rasa hormat percaya diri dari dari orang-orang yang dipimpinnya, (2) inspirational motivation, yaitu pemimpin sebagai pemberi semangat untuk membangkitkan antusiasme dan optimism orang-orang yang dipimpinnya, (3) intellectual stimulation, yaitu pemimpin selalu menggali ide-ide baru dan solusi yang kreatif dari pada orang-orang yang dipimpinnya dan mendorong untuk mempelajari dan mempraktekan pendekatan baru dalam melakukan pekerjaannya, dan (4) individualized consideration, yaitu pemimpin yang dapat merefleksikan dirinya sebagai orang yang penuh perhatian dalam mendengarkan dan menindaklanjuti keluhan, ide, harapan-harapan, dan masukan dari orang yang dipimpinnya (Aan Komariah, 2005:80).

Kualitas kepemimpinan pendidikan yang inovatif berikutnya adalah profesional. Pemimpin pendidikan akan dapat memimpin secara profesional apabila ia memiliki kemampuan dan motivasi yang tinggi dalam memimpin. Karena pemimpin tidak akan dapat memimpin secara profesional, jika ia hanya memliki kemampuan saja atau motivasi saja. Oleh karena itu, pada kepemimpian yang inovatif kemampuan dan motivasi kerja yang tinggi harus terintegrasi dalam kepemimpinannya (Ibrahim, 1992: 5).

Pemimpinan pendidikan yang inovatif harus dapat melaksanakan kepemimpinannya secara: (1) konstruktif, yaitu pemimpin pendidikan yang inovatif senantiasa mendorong dan membina pendidik dan tenaga kependidikan agar berkembang menjadi pendidik dan tenaga pendidikan yang professional, (2) kreatif, yaitu pemimpin pendidikan yang inovatif dalam meningkatkan profesionalisme pendidik dan tenaga kependidikan selalu mencari gagasan baru (inovasi) agar dicapai peningkatakan mutu pendidikan sesuai dengan yang diharapkan, (3) delegatif, yaitu pemimpin pendidikan yang inovatif dalam meningkatkan mutu pendidikan selalu berusaha mengintegrasikan dan mensinergikan semua kegiatan sehingga dapat mencapai tujuan pendidikan secara efektif dan 
efesien, (4) rasional dan objektif, yaitu kepemimpinan perndidikan yang inovatif dalam meningkatkan profesionalisme pendidik dan tenaga kependidikan selalu menggunakan pertimbangan yang rasional dan objektif, (5) pragmatis, yaitu kepemimpinan pendidikan yang inovatif dalam meningkatkan pendidik dan tenaga kependidikan selalu menetapkan target berdasarkan kemampuan masing-masing pendidik dan tenaga kependidikan, (6) keteladanan, yaitu kepemimpinan pendidikan yang inovatif dalam meningkatkan profesionalisme pendidik dan tenaga kependidikan dengan memberikan contoh atau keteladanan, (7) adaptasi dan fleksibel, yaitu kepemimpinan pendidikan yang inovatif dalam meningkatkan profsionalisme pendidik dan tenaga kependidikan harus punya kemampuan beradaptasi dan fleksibel dalam menhadapi situasi-situasi baru, serta kemampuan dalam menciptakan sitausi yang menyenangkan bagi pendidik dan tenaga pendidikan dalam melaksanakan tugas (Mulyasa,2005:118).

Kepemimpinan pendidikan yang inovatif harus memiliki kompetensi sesuai dengan standar yang telah ditetapkan. Kompetensi yang dimaksud antara lain: (1) menfasilitasi pengembangan, penyebarluasan, dan pelaksanaan pembelajaran yang dikomunikasikan dengan baik sehingga didukung oleh komunitas sekolah, (2) membantu, membina dan mempertahankan lingkungan sekolah dan program pengajaran yang kondusif bagi proses pembelajaran peserta didik dan pertumbuhan profesional pendidik dan tenaga kependidikan, (3) menjamin bahwa pengoperasian sumber daya manusia yang digunakan untuk menciptakan lingkungan belajar yang aman, sehat, efisien dan efektif, (4) bekerjasama dengan orang tua murid dan anggota masyarakat, menanggapai kepentingan da kebutuhan komunitas yang beragam, dan memobilsasi sumber daya masyarakat, memahami, dan mempengaruhi lingkungan politik, sosial ekonomi dan buadaya yang lebih luas (Agus Dharma, 2003:39). Kepemimpinan pendidikan yang inovatif harus mempunyai tanggung jawab. Tanggung jawab itu diperlukan: (1) agar tercipta lingkungan belajar yang kondusif yang memungkinkan pendidik dan tenaga kependidik mendayagunakan dan mengembang-kan potensi yang dimilikinya secara optimal. Lingkungan belajar yang kondusif terserbut diwujudkan dengan (a) penciptaan lingkunngan fisik yang kondusif bagi guru dan tenaga kependidikan dalam melaksanakan tugas, (b) penciptaan suasana yang tenang dan menye-nangkan bagi pendidik dan tenaga kependidikan dalam bekerja, (c) menanamkan disiplin pada semua komunitas di intitusi pendidikan, (d) menumbuhkan dorongan instrinsik dan ekstrinsik bagi guru dan tenaga kependidikan, (e) memberikan penghargaan secara tepat, efektif dan efisien kepada guru dan tenaga kependidikan, dan (f) penyediaan berbagai sumber yang dibutuhkan guru dan tenaga kependidikan di sekolah. Penciptaan lingkungan belajar yang kondusif oleh kepeminpinan pendidikan yang inovatif harus memperhatikan beberapa prinsip:

penciptaan kegiatan guru dan kegiatan guru dengan kegiatan yang menarik dan menyenangkan, menjadikan guru dan tenaga sebagai penanggung jawab kegiatan untuk mencapai tujuan, meninformasikan hasil kegiatan yang telah dicapai oleh guru dan tenaga kependidikan, memberikan reward bagi yang berprestasi dan phunisman bagi yang melamnggar aturan, dan memenuh kebutuhan dan rasa aman bagi guru dan tenaga kependidikan dalamm bertugas, (2) membina dan mem- bimbing guru dan tenaga kependidikan agar mereka memiliki kemampuan mengarahkan diri mereka sendiri dari kurang berpengtahuan menjadi berpengetahuan, dari diarahkan orang lain menjadi mampu mengarahkan diri sendiri, dari tidak profesinoal menjadi profesional, (3) menumbuhkan kreativitas guru dan tenaga kependidikan untuk mencipatakan sesuatu yang baru yang berthargha untuk kemanuuan pendidikann, dan (4) menggunakan strategi yang tepat agar guru dan tenaga kependidikan dapat bekerja efektif untuk mencapai tujuan yang telah ditetapkan (Agus Dharma, 2003:41).

Seorang pemimpinan pendidikan yang inovatif harus mempunyai keyakinan diri agar dapat bekerja dengan baik dan bersungguhsungguh dalam melaksanakan tugas dan kewajibannya sebagai seorang pemimpin. Keyakinan diri tersebut antara lain : Pertama, 
keyakinan bahwa pekerjaan yang dilakukan itu merupakan ibadah, karena itu ia tidak mau melakukan perbuatan yang tercela dan memberikan kesempatan kepada pendidik dan tenaga kependidikan untuk melakukan perbuatan tercela tersebut, karena perbuatan tersebut dapat merusak citra dirinya dan citra lembaga pendidikan yang dipimpinnya.

Kedua, keyakinan bahwa pendidik dan tenaga kependidikan memiliki harpan dan kinerja yang tinggi. Oleh karena itu, keputusan manajerial yang dimabilnya bersama pendidik dan tenaga kependidikan untuk meningkatkan mutu pendidikan dilakukan dengan melakukan inovasi terhadap berbagai komponen pendidikan. Selain itu, kepemimpinan pendidikan yang inovatif harus dapat menggunakan pengaruh kepemimpinnya secara produktif untuk meuwujudkan haparan pendidik dan tenaga kependidikan dalam melakukan inovasi terhadap pelaksanaan tugasnya di lembaga pendidikan.

Ketiga, keyakinan diri bahwa pendidik dan tenaga kependidikan perlu ditumbuhkan minatnya untuk mau mempelajari teknologi baru dalam pendidikan. Hanya dengan mempelajari dan memanfaatkan teknologi baru dalam pendidikan diharpakan terjadi peningkatan mutu pendidikan di sekolah.

Keempat, keyakinan diri bahwa perlu pengembangan profesional guru dan tenaga kependidikan sebagai bagian integral dari peningkatgan mutu institusi pendidikan. Karena itu ia selalau mencari peluang untuk meningkatkan profesional dirinhya, pendidik dan tenaga kependidikan pada institusi pendidikan yang dipimpinnya, melalui pemanfaat berbagai sumber belajar baik berupa human resources, priented resources, enviromental resources dan audio visual resources.

Kelima, keyakinan bahwa keragaman komunitas di institusi pendidikan sebagai aset memperkaya institusi pendidikan. Hal ini dapat dilakukan melalui sharing of experience. Sharing of experience didasarkan kepada asumsi bahwa guru dan tenaga kependidikan adalah orang yang memiliki pengalaman yang berbeda baik karewna latar belakang pendidikan, pengalaman bekerja, pernbedaan lokasi tempat tugas dan sebagainya, (Fidaus Cs, 2006:1). Jika pengalaman masing-masing guru dan tenaga kependidikan dapat dirumuskan secara sistimatis dan tersruktur akan menjadi pengalaman baru dan milik bersama yang dapat dimanfaatkan dalam melakukan inovasi pada intitusi pendidikan untuk menghasilkan pendidikan yang bermutu.

Keenam, keyakinan bahwa pada insitusi pendidikan harus tercipta iklim belajar yang menyenangkan yakni suasana yang dapat memberikan dorongan kepda peserta didik untuk mencapai prestasi yang tinggi. Meujudkan iklim tersebut dapat dilakukan dengan berbagai cara: (1) menata dan memperindah lingkungan fisik sehingga peserta didik merasa aman dan nyaman dalam bellajar, (2) menciptakan lingklungan emosional dengan mewujudkan jalinan pengertian, hubungan yang akrab dan harmonis, (3) memberikan tantangan kepada peserta didik yang memberikan peluang kepada mereka untuk mempeoleh keberhasilan, (4) mengembangkan potensi peserta didik sesuai dengan kebutuhan hidupnya, (5) menumbuhkan kemandirian belajar pada peerta didik, sehingga mereka gemar belajar, (6) mendorong peserta didik untuk mengembangkan dirinya secara optimal sehingga mereka memiliki motivasi yang tinggi dalam mengembangkan ilmunya.

Ketujuh, keyakinan bahwa keberadaan institusi pendidikan merupakan bahgian integral dari masyarakat karena itu ia selalu berusaha melakukan inovasi pada institusi pendidikannya dengan melibatkan masyarakat dalam upaya meningkatan mutu pendidikan, sehingga hasil pendidikan tersebut dapat memenuhi kebuhan masyarakat. Hal ini dilakukan dengan cara menghasilkan lulusan pendidikan yang mau dan mampu meningkatkan kualitas kehidupan masayarakat, menciptakan ide-ide baru yang mampu mendinamiskan kehidupan masyarakat. Jika hal ini dapat dicapai tentu masayarakat dengan kesadaran dan penuh tanggung terlibat secara aktif dan dinamis dalam mensukseskan program institusi pendidikan yang dipimpinnya (Aus Dharma, 2003:44-46).

\section{SIMPULAN}

Kebijakan pemerintah dengan diberlakukannya otonomi pendidikan perlu diiringi dengan perubahan kepemimpinan pendidikan di 
tingkat sekolah. Kepemimpinan pendidikan yang cocok di era otonomi pendidikan itu adalah kepemimpinan pendidikan yang inovatif. Kepemimpinan pendidikan yang inovatif untuk dapat melakukan inovasi (perubahan) pada lembaga pendidikan yang dipimpinnya harus memiliki visi, misi, kemauan dan komitmen untuk berinovasi (berubah) dan memahami proses inovasi, pengelolaan inovasi serta memiliki keahlian dan kualitas. Keahlian yang harus dimiliki oleh kepemimpinan yang inovatif adalah keahlian dalam manajerial dan kepemimpinan. Keahlian manajerial diperlukan agar pemimpin mampu menangani komplesitas intitusi pendidikan, keahlian kepemimpinan pendidikan diperlukan agar diperoleh pemimpin yang inovatif dalam memimpin institusi pendidikan agar sesuai dengan harapan otonomi pendidikan.

\section{DAFTAR RUJUKAN}

Arcaro, M Jerome, S. 2005. Pendidikan Berbasis Mutu, Jakarta : Pustaka Pelajar

Agus Dharma, 2003, Standar Kompetensi Kepala Skolah, Jakarta: Pusdiklat Depdiknas.

Danim Sudarwan, 2002, Inovasi Pendidikan : Dalam Upaya Meningkatkan Profesionalisme Guru, Bandung Pustaka Setia.

Departemen Agama RI, 2006, Model-Model Pelatihan Bgi Pengawas Sekolah, Jakarta: Direktorat Jenderal Pendidikan Islam, Durektorat Pendidikan Madrasah.
Everett M. Rongest, 1983, Diffusion of Innovasion, The Free Press A division of Macmillan Publishing Co. Inc New York.

Ibrahim, 1988, Inovasi Pendidikan, FIP, IKIP Malang.

Irajasah, 2011, Berfikir Induktif dan Deduktif, Word Press Com, 2011/06/01.

M. Rongers, Everett, 1993, Diffusin of Inovation, New York: The Free Press A. Division of Macmillan Publishing, C.)

Mulyasa, E., 2005, Menjadi Kepala Sekolah Profesional, Bandung: PT. Remaja Rosdakarya.

Komariah, Aan dan Cepi Triatna, 2005, Visionary Leadership Menuju Sekolah Efektif, Jakarta : PT Bumi Aksara.

Redaksi Sinar Grafika, Peraturan Pemereintah Republik Indonesia Nomor 19 Tahun 2005 Tentang Standar Nasional Pendidikan, Jakarta : Sinar Grafika.

Syam, Aminuddin, 2006, Implementasi Pendidikan Seumur Hidup Makalah Disajikan pada diskusi Dosen, Sekolah Tinggi Ilmu Tarbiyah Syekh Burhanuddin, Pariaman, tanggal 19 Pebruari 2006.

Umaidi, 1999, Sebuah Pendekatan Baru Dalam Pengelolaan Sekolah Untuk Peningkatan Mutu, Jakarta: Departemen Pendidikan dan Kebudayaan 